\title{
Investigation on the Day-to-day Behavior of a Taiwanese Nursing Organization's Residents through Shared Bedroom Style
}

\author{
Yenping Hsieh
}

Assistant Professor, Department of Healthcare Administration, Asia University of Taiwan, Taiwan

\begin{abstract}
The purpose of this study is to explore the behaviors of the residents of a Taiwanese nursing organization through their style of sharing bedrooms with other residents. This study examines day-to-day behaviors, and the differences and connotations. The investigation employs the environmental behavioral observation method in order to observe and maintain records of the residents' behavior. As per this method, there are six types of behaviors, namely, basic behavior, quiet behavior, social interaction behavior, recuperation behavior, mobile behavior, and leaving the bedroom (social withdrawal behavior). These behaviors are studied in the context of two shared-room styles, namely, two-person bedrooms and six-person bedrooms. It was found that residents sharing two-person bedrooms exhibit an increase in withdrawal behavior; however, they are more active than residents sharing six-person bedrooms, in terms of basic behavior and social interactions. Thus, this study finds that the number of residents sharing a bedroom influences their day-to-day behavior.
\end{abstract}

Keywords: Nursing Organization; shared bedroom; day-to-day behavior

\section{Introduction}

In 2008 , the elderly accounted for $10.3 \%$ of Taiwan's population, and this figure is slated to reach $14 \%$ by 2018, a situation of such rapid growth indicates that the importance of long-term elderly care has become critical. Owing to this need, medical institutions have evolved into organizational accommodations, providing medical care and services to improve the physical fitness and health of their residents. To this end, rooms have evolved from being ward units to spaces providing privacy and a variety of facilities (Wang and Kou, 2005). This change shows that greater attention is now being paid to the residents' quality of life.

According to many literatures, private bedrooms are better than shared bedrooms since they enhance the residents' independence, dignity, and privacy. Studies rarely discuss whether the behavior of residents in shared bedrooms is dictated by the demands of private bedrooms taking advantage of the time concept. This paper observes how time is spent on day-to-day behaviors by the residents of medical organizations, and examines the differences and connotations.

\footnotetext{
*Contact Author: Yenping Hsieh, Assistant Professor, Department of Healthcare Administration, Asia University of Taiwan Tel: +886-4-23323456\#1821

E-mail: yenping@asia.edu.tw

(Received October 6, 2009 ; accepted May 17, 2010)
}

\subsection{Theories regarding the elderly and their environments}

In this section, this study examines existing theories regarding the elderly and their interactions with their environments. Lewin (1951) proposed the function concept, according to which B (Behavior) $=\mathrm{F}$ (Person, Environment). This implies that human behavior is the result of interactions between the individual and their surrounding environment. Two definitions of the influence of the environment on ageing are widely accepted by researchers.

The first was given by Lawton and Eisdorfer (1973), who proposed the ecology model (also known as the Competence-Press Model). According to this theory, the adjustment competence of the elderly is the result of a constant interaction between body, psychology, and the environment. Thus, the disabled elderly are influenced by their environment much more than those who are healthy, as the latter have the capacity to look for a suitable environment using the resources available to them (Lawton 1998a, 1998b, 1999).

Kahana (1982) proposed the Person-Environment Congruence Model, and argued that if there were no congruence between the needs of the elderly and their environment, they would fail to adapt well, which would influence their physical and psychological state.

Regarding environmental influences on residents, specifically, their bedrooms. Past researches have proposed that privacy, control, individualization, and private space are important to residents, concerning the relation between individuals and environments, from 
the perspective of rooms in medical institutions (terms are defined below). Emphasis has also been placed on psychological factors, such as dignity, selection, and self-expression (Bowie et al., 1992; Moos and Lemke, 1996; Lawton, 2001; Sloane et al., 2002). Thus, the importance of private bedrooms is evident.

\subsection{Privacy}

According to existing literature, a key factor influencing the residents of institutions is having the option of visitors (Chaudhury et al., 2005; Ulrich and Zimring, 2004). Furthermore, a study by Sumeragei et al. (2002) pointed out that, residents living in private rooms had a higher degree of satisfaction over those occupying shared rooms. Duffy et al. (1986) conducted a study on both residents and management of nursing homes and found that managers preferred rooms conducive to social interactions (shared rooms), while residents preferred private rooms.

In fact, Mosher-Ashley and Lemay (2001) pointed out that residents with shared rooms preferred to change to private rooms. Terakaw (2004) studied the residents of medical institutions who had moved from shared rooms to private rooms, and results showed that the residents who formerly disliked private rooms began to prefer them after eight months. This suggests that satisfaction with the type of room depends on experience. This also suggests that residents ultimately prefer to live in private rooms.

Westin (1967) proposed that for the majority of people, privacy implies four key points, namely, communication, self-control, free expression of personal matters, and privacy. Communication implies the protection and secrecy regarding personal information. Self-control refers to the independent ability to decide one's feelings, or the absence of a sense of powerlessness. Free expression of personal matters and the freedom to openly express one's feelings in the privacy of one's room, refer to the absence of being under observation. Thus, if privacy were recognized as an important aspect of living, it would help nurture individualism and independence among the elderly.

Another fact supporting privacy is the existence of negative communication between residents sharing bedrooms. Inoue et al. (1997) pointed out that, compared with residents of private rooms, residents living in multiple-occupancy rooms would obviously refuse to be in contact with others while sleeping or doing something quietly. Morgan and Stewart (1999) pointed out that, two-person rooms provide fewer opportunities for social interactions, and the residents may clash with each other (Sumeragei et al., 2002). However, Bitzan (1998) presented a more positive picture, stating that residents sharing rooms have positive interactions with each other. Thus, it is concluded that while evidence largely points to negative communication between residents sharing rooms, a supportive relationship may also exist between them.

\subsection{Control}

With regard to self-control, clashes are observed between residents sharing rooms. Residents sharing two-person rooms would have problems, such as having their own space and privacy (Sumeragei et al. 2002). Other problems include, a preference for television/radio stations, television/radio turned on or off, the volume, inconsistent bedtimes, curtains open or drawn, door to corridor open or closed, room lighting issues, decorative preferences, etc. (Foltz-Gray, 1995; Harris et al., 2002; Kaldenberg, 1999; Kane et al., 1998; Ulrich and Zimring, 2004). Willcocks et al. (1987) mentioned that the residents' degree of satisfaction would be lower when unable to control their environment. Thus, a private bedroom would enable them to freely express their personality, within their own space, and under their control, which would in turn improve the quality of their life.

\subsection{Individualization and private space}

One example of a researcher's study on individualization and private space is Goga et al. (2002), who studied the objects and keepsakes of residents of long-term care institutions. The study showed that their day-to-day necessities numbered 32 items $(74 \%)$, of which 11 objects $(26 \%)$ were personal, for decoration, of sentimental value, etc. However, in the case of elderly residents with serious dementia, the number of possessions was fewer and their living conditions in the organization were markedly different from their former way of life. This is also an important point of difference between residents of shared and private rooms. Inoue et al. (1997) found that residents of private rooms continue to live as they did before entering the organization, and thus, tend to have more possessions in their room than residents of shared bedrooms. Tachibana et al. (1997) investigated this phenomenon and found that, residents of private rooms would gradually bring more of their possessions into their bedroom, and the more possessions they had, the more they tended to personalize and arrange their bedroom to freely conduct their preferred leisure activities. Thus, over time, residents adapt to their new living space and personalize it to reflect their personality and feelings. These facts indicate that residents of shared bedrooms have more difficulty in showing their unique personality through their room.

\subsection{History of Taiwanese long-term care institutions} and analysis of shared bedrooms

\subsubsection{History of long-term care institutions in} Taiwan

Long-term care institutions in Taiwan in the 1980s mainly served to provide relief and shelter to the poor. At that time, elderly people constituted less than 4 per cent of the population, and they were taken care of by individuals and their families. Unregistered care 
institutions appeared in Taiwan in 1985, and gradually, issues of quality, security, etc. began attracting attention. Thus, standards for care institutions were established in 1993, and the welfare law for the elderly was revised in 1997, a ten-year plan was adopted, and a long-term care plan was implemented in 2007. The number of nursing schools in Taiwan grew from 183 in 1999, to 992 by 2007. Soon, these institutions evolved from unregistered organizations to safe and legal registered organizations. Thereafter, the purpose of these institutions expanded from merely providing relief to the poor to providing diversified long-term care (Chuang, 2008).

\subsection{Familiarity of surroundings as a means to increase residents' comfort level}

Studies show that residents feel more strongly about items in their immediate environment, as compared to their family members or the nursing personnel, such as disliking living with roommates who become ill, and the inconvenience of sharing bed-side equipment (Yang, 2001). Studies on the residents' ability to adapt to an organization show that they adapt better when they are given due privacy, and allowed to bring familiar items such as photos of family members, their own furniture, etc. (Chang and Wu, 2003). Studies on nursing home bedrooms showed that, their most important role was to enable residents to continue their day-to-day living as they did prior to joining the organization. Thus, institutions attempt to humanize bedroom spaces according to, states of physical functions, security, amenities, privacy, convenience, and care convenience (Tzeng and Wang, 2002). It is also important to combine the right kinds of residents. For instance, Hsu et al. (2004) pointed out that residents with dementia living with those without dementia would lead to increased turbulent behavior, which would stem from non-recognition functions. All this evidence serves as an argument for bedrooms that help residents become comfortable in unfamiliar surroundings.

\subsection{Behavior of residents sharing bedrooms}

Huang et al. (2008) studied the residents of Unit Care, a new care model of Taiwanese nursing organizations. The study showed that in the seventh week, residents left their beds after 2980 minutes, which increased to 3411 minutes in the 16th week. This increase in the time required to leave their beds showed that they had good social interactions with other residents in the drawing room, which is evidence that residents of private rooms communicate more with other residents.

\subsection{Institutional rooms compared with Taiwanese homes}

According to an investigation of houses in Taiwan in 2007, it was found that the average area of each household was $135.8 \mathrm{~m}^{2}$; each member had 1.1 rooms on average, an average area of $42.9 \mathrm{~m}^{2}$, and most were accustomed to living one person per room. However, as per the Taiwan welfare organizational standards, each bedroom in long-term care institutions is more than $7 \mathrm{~m}^{2}$, with a maximum of six beds per room. Thus, residents of these care institutions at present are mainly sharing rooms. Therefore, institutions must respond accordingly to the living environment demands of the elderly.

\section{Data Sources and Sampling}

This study investigates the residents of a care organization in Taiwan, which was established in 2001. It is a three-story building, with residents housed on all three floors, for a total of 80 beds; 16 beds in doubleoccupancy rooms, and 64 beds in multi-occupancy ( 6 beds per room) rooms, in 16 rooms. Figures 1 and 2 represent a six-person bedroom and a two-person bedroom, respectively. Each resident is permitted to use one bed with a cabinet beside the bed. The arrangement of beds presented, as by Tzeng and Wang (2002), is similar to the arrangement found in this organization.

Data collection was conducted from October 2006 to March 2007. In consideration of resident's weekend visitors, observations were conducted on weekdays, between $7 \mathrm{AM}$ and $7 \mathrm{PM}$, for three days. The observer recorded relevant details of the residents' behavior in their rooms, as well as the time of each behavior's behavioral occurrences.

The purpose of the study, its processes, and the participants' rights were explained to the residents. Participants understanding and willing to participate in the study signed a permission/consent letter, after which the observations began. In the case of residents unable to communicate, the purpose of the study was explained to their legal representative, and observations began upon obtaining the permission/consent letter. Altogether, 47 residents signed the permission/consent letters, agreeing to individual observation.

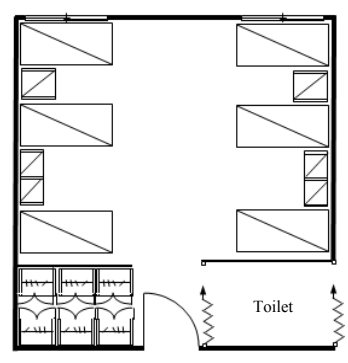

Fig.1. Six-person Bedroom

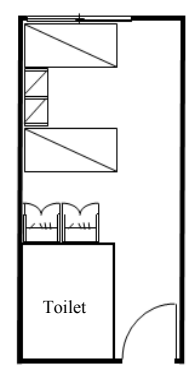

Fig.2. Two-person Bedroom

\section{Method}

This study is conducted on the basis of the definition of day-to-day behaviors, as proposed by Nakanishi (2004). As per this definition, day-to-day behaviors include the physical demands of life, and maintaining a high level of social activity, with a daily repetition of actions, activities influenced by prevalent culture, and individual habits. Thus, this study adopts environmental behavior observations and investigation 
methods in order to reflect the actual behavior of residents in their rooms. This method required a large amount of time and operational items, since elderly behavior was the only parameter, making it difficult to precisely analyse the psychological factors. However, in cases of residents with health problems, such as severe disabilities or dementia, that is, residents who found it difficult to express themselves, their behavior could be directly recorded and analysed.

The residents' day-to-day behaviors were classified by Kumsuek et al. (1994), into five kinds, namely; 1) basic behaviors, including dining, excretion, cleaning, and dressing; 2) quiet behaviors, including sleeping during the day, being in a trance, and staring at a fixed point; 3) social interaction behaviors, including chats between residents, with family members, and with care personnel; 4) recuperation behaviors, including examinations, treatments, and rehabilitation activities; 5) mobile behaviors, including purposeless movement. Apart from these five, this study adds voluntary response behaviors, which includes leaving one's room in response to various day-to-day requirements. Thus, there are six kinds of behaviors.

The observers are trained in the classification of all day-to-day behaviors, recording patterns, determining the start points of records, and how to observe the subjects. The observers made a record of the behaviors of each resident, conducted every three days, and each record adopted a sub-record. If the observer found a behavior they were unable to classify, it was submitted to a study group for discussion, from detailed records. Apart from this investigation, observers also collected the residents' basic data, such as their age, gender, type of illness, and Activities of Daily Living (ADL).

\section{Data Management}

Once classified, each behavior was averaged for three days. The total amount of time spent on all of the behaviors recorded during three days exceeded 720 hours. A total of 106 items of resident's behaviors are recorded. In order to determine which behaviors occurred most often, and any behaviors not exceeding one minute ( 27 behaviors in all), as per the three-day average, are deleted from the total number, thus, 79 valid behaviors are obtained, and then classified into the six categories, as mentioned above. The statistics software SPSS 12 is used to analyse the average, standard deviation, percentage, and Kruskal-Wallis one-way analysis of variances, by rank, etc.

\section{Results}

\subsection{Basic attributes and day-to-day behavior of residents}

Table 1. shows the demographic break-down, educational levels, and health conditions of the subjects. The average age of the residents is 79.7 years (SD: 9.5 years), the ADL average score is 33.6 points (SD: 31.3 points), and the IADL average score is 23.4 points (SD: 7.4 points). Each unwell resident suffered from 1.8 illnesses on average; and of these, most are strokes or heart disease.

Table 2. shows the day-to-day behaviors of the residents in their rooms. The average observation time is 720 minutes. From maximum to minimum, their behaviors are as follows: leaving the bedroom 2395.5 per cent; quiet behavior 2056.9 per cent; basic behavior 112 per cent; social interactions 64.8 per cent; mobile behaviors 46.3 per cent, and recuperation behaviors 11.4 per cent.

\subsection{Day-to-day behavior in rooms}

Table 3. shows the average time spent on day-today behavior in six-person and two-person bedrooms. In six-person bedrooms, behavior seems to occur in

Table 1. Socio-demographic and Health Characteristics of the Study Sample

\begin{tabular}{llllll}
\hline Characteristic & \multicolumn{5}{l}{ Characteristic } \\
\hline \multicolumn{1}{l}{ age group } & $\%$ & $\mathrm{~N}$ & Mean & s.d. \\
$65-69$ & 6.4 & 3 & Age & 79.7 & 7.5 \\
$70-74$ & 12.8 & 6 & ADL score & 33.6 & 31.3 \\
$75-79$ & 10.6 & 5 & IADL score & 23.4 & 7.7 \\
$80+$ & 70.2 & 33 & $\begin{array}{l}\text { Lengthe of residence in } \\
\text { institution living, mooths }\end{array}$ & 27.1 & 15.6
\end{tabular}

Gender

Female $\quad 55.326$ Measures of frailty:

$\begin{array}{llllll}\text { Male } & 44.7 & 21 & \text { Stroke } & 40.4 & 19\end{array}$

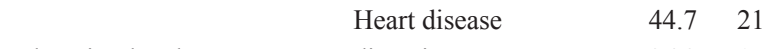

$\begin{array}{llll}\text { Education level } & \text { dimecia } & 36.2 & 17.0\end{array}$

$\begin{array}{llllll}\text { Illiterate } & 57.4 & 27 & \mathrm{SD} & 23.4 & 11.0\end{array}$

$\begin{array}{llllll}\text { Elementary school } & 29.8 & 14 & \text { other chronic disease } & 27.7 & 13.0\end{array}$

Junior high school $6.4 \quad 3$

Senior high school $6.4 \quad 3$

Notes : ADL=Activities of Daily Living. IADL=Instrumental Activities of Daily Living. s.d. standard deviation. Sample size is 47 .

Table 2. Six Items of Daily Life Behavior

\begin{tabular}{|c|c|c|c|c|c|}
\hline $\begin{array}{l}\text { Daily life } \\
\text { behavior }\end{array}$ & Sum & $\begin{array}{c}\text { Accounts for } 720 \\
\text { points of rates }\end{array}$ & Mean & S.D. & Behavioral content \\
\hline Basic behavior & & & & & Examples of 30 items \\
\hline Diet & 108.8 & 15.1 & 4.5 & 16.5 & $\begin{array}{l}\text { Breakfast,lunch and dinner, the behavior } \\
\text { beyond the breakfast,lunch and dinner, } \\
\text { such as drinking tea, eat the pastry, irritate } \\
\text { behaviors such as the food, etc. }\end{array}$ \\
\hline Excretion & 342.6 & 47.6 & 14.3 & 49.9 & $\begin{array}{l}\text { Including the behavior of in charge ofing etc. } \\
\text { that the toilet, change the diaper or urine }\end{array}$ \\
\hline Cleanness & 61.8 & 8.6 & 2.6 & 9.3 & $\begin{array}{l}\text { Behavior of having a bath or taking a sponge } \\
\text { bath etc. }\end{array}$ \\
\hline $\begin{array}{l}\text { Put the appearance } \\
\text { in order }\end{array}$ & 100.9 & 14.0 & 4.2 & 14.5 & $\begin{array}{l}\text { Put the appearance in order, change and wear } \\
\text { the clothes, undress }\end{array}$ \\
\hline $\begin{array}{l}\text { Put the } \\
\text { environment in } \\
\text { order }\end{array}$ & 192.3 & 26.7 & 8.0 & 28.0 & $\begin{array}{l}\text { Internal environment it make up bedroom, } \\
\text { until last clotheses one's own, last article, put } \\
\text { in order cotton-wadded quilt,etc. build }\end{array}$ \\
\hline Total & 806.4 & 112.0 & 17.2 & 20.8 & \\
\hline Quiet behavior & & & & & Examples of 5 items \\
\hline Sleep & 6578.6 & 913.7 & 139.9 & 83.7 & Sleep on the bed \\
\hline $\begin{array}{l}\text { Sit on the chair } \\
\text { wheelchair or bed }\end{array}$ & 16080.9 & 2233.5 & 175.1 & 105.2 & $\begin{array}{l}\text { Stay seat in the chair, the wheelchair or } \\
\text { behavior in bed }\end{array}$ \\
\hline Total & 14809.8 & 2056.9 & 315.1 & 142.6 & \\
\hline $\begin{array}{l}\text { Social } \\
\text { intercourse } \\
\text { behavior }\end{array}$ & 466.9 & 64.8 & 9.9 & 21.2 & $\begin{array}{l}\text { Examples of } 7 \text { items. Initiative or passive } \\
\text { and room-mate, look after personnel, the talk } \\
\text { between relatives ets. }\end{array}$ \\
\hline $\begin{array}{l}\text { Recuperation } \\
\text { behavior }\end{array}$ & 82.1 & 11.4 & 1.7 & 3.2 & $\begin{array}{l}\text { Examples of } 10 \text { items.Check or medical } \\
\text { treatment is correlated with the behavior of } \\
\text { handling, such as taking medicine, change } \\
\text { dressings, behaviors of observing etc. }\end{array}$ \\
\hline Mobile behavior & 333.1 & 46.3 & 7.1 & 8.3 & $\begin{array}{l}\text { Examples of } 26 \text { items.No matter by the } \\
\text { purposeless movement, the people or } \\
\text { treatment personnel live to help to move } \\
\text { from some o'clock to the behavior at some } \\
\text { o'clock. }\end{array}$ \\
\hline $\begin{array}{l}\text { Leaving } \\
\text { bedroom }\end{array}$ & 17247.8 & 2395.5 & 367 & 152.8 & $\begin{array}{l}\text { The time to leave the bedroom, it is one } \\
\text { altogether }\end{array}$ \\
\hline
\end{tabular}


the following order: leaving bedroom, quiet behavior, basic behavior, mobile behavior, social intercourse behavior and recuperation behavior. On the other hand, in two-person bedrooms, the behaviors occur in the following order: quiet behavior, leaving bedroom, social interaction behavior, basic behavior, recuperation behavior and mobile behavior. Two different styles of behavior times occurred in shared bedrooms.

The most common behavior in the six-person rooms was leaving the bedroom; while it was quiet behavior in the two-person bedrooms. With regard to quiet behavior, residents in two-person bedrooms spent more time sleeping than those in six-person bedrooms. There is little difference between the two kinds of bedrooms with regard to time spent being idle, such as while sitting in a chair, bed, or wheelchair. With regard to basic behaviors, although neither type of resident spent much time on this behavior, the time spent was higher in the two-person bedrooms than in the sixperson rooms. Finally, with regard to social interaction behaviors, the residents of the two-person bedrooms spent more than five times the amount of time than that spent by residents of the six-person bedrooms.

This study examines whether the type of room has an impact on the day-to-day behaviors of the residents, by using the Kruskal-Wallis one-way analysis of variance by rank. The results show that the room type makes no difference to leaving the bedroom $\left(\chi^{2}=\right.$ $0.367, \mathrm{p}=0.545)$, to quiet behaviors $\left(\chi^{2}=0.001, \mathrm{p}=\right.$ $0.975)$, to mobile behaviors $(\chi 2=0.538, \mathrm{p}=0.463)$, to social interaction behaviors $\left(\chi^{2}=1.880, \mathrm{p}=0.170\right)$ or to recuperation behaviors $\left(\chi^{2}=1.185, \mathrm{p}=0.276\right)$. There was, however, a difference in basic behaviors, $\left(\chi^{2}\right.$ $=6.751, \mathrm{p}=0.009$ ).

Research shows a functional assessment of residents, and how the recognition function influences their behaviors in their rooms (Tzeng and Wang, 2002; Hsu et al. 2004). Thus, this study employs the KruskalWallis one-way analysis of variance by rank, in order to examine the function assessment of two-person bedrooms and six-person rooms, and analyses whether the dementia of residents causes a difference in their day-to-day behaviors (Table 3.). The results show that there is no difference in ADL between residents of two-person bedrooms and six-person bedrooms. With regard to residents suffering from dementia, there is a difference with regard to recuperation behaviors in six-person rooms $\left(\chi^{2}\right.$ value $=6.20, p$ $=0.013)$, and to social interaction behaviors in twoperson rooms $\left(\chi^{2}\right.$ value $\left.=3.85, \mathrm{p}=0.05\right)$. From the perspective of time, the average recuperation time of residents, without dementia, in six-person rooms is 1.61 minutes (SD: 0.54$)$, which is higher than that of residents with dementia, at 0.53 minute (SD: 0.45). The average time spent on social interaction behaviors by residents, without dementia, in two-person rooms is 64.33 minutes (SD: 8.41), which is higher than that of residents with dementia, at 2.01 minutes (SD: 1.01).
Table 3. Six-person Bedroom and Two-person Bedroom of Daily Life Behavior

\begin{tabular}{|c|c|c|c|c|c|c|c|c|}
\hline & \multicolumn{3}{|c|}{ six-person bedroom } & \multicolumn{5}{|c|}{ two-person bedroom } \\
\hline & & & ADL & Dementia & & & ADL & Dementia \\
\hline & Mean & s.d. & $\chi^{2}$ & $\chi^{2}$ & Mean & s.d. & $\chi^{2}$ & $\chi^{2}$ \\
\hline basic behavior & 15.81 & 3.17 & $8.37^{\mathrm{ns}}$ & $0.30^{\mathrm{ns}}$ & 26.34 & 9.68 & $0.77^{\mathrm{ns}}$ & $1.19^{\mathrm{ns}}$ \\
\hline Diet & 2.21 & 1.02 & & & 3.06 & 1.48 & & \\
\hline Excretion & 7.15 & 1.91 & & & 8.22 & 4.92 & & \\
\hline Cleanness & 0.64 & 0.34 & & & 5.92 & 2.26 & & \\
\hline Put the appearance in order & 1.87 & 0.37 & & & 4.07 & 1.73 & & \\
\hline Put the environment in order & 3.95 & 1.06 & & & 5.07 & 3.01 & & \\
\hline quiet behavior, & 307.40 & 20.89 & $5.38^{\mathrm{ns}}$ & $2.81^{\text {ns }}$ & 367.75 & 81.90 & $2.142^{\mathrm{ns}}$ & $1.19^{\mathrm{ns}}$ \\
\hline Sleep & 130.17 & 73.15 & & & 206.93 & 124.49 & & \\
\hline $\begin{array}{l}\text { Sit on the chair wheelchair or } \\
\text { bed }\end{array}$ & 177.23 & 104.16 & & & 160.8 & 121.0726 & & \\
\hline social intercourse behavior & 6.53 & 2.56 & $3.94^{\mathrm{ns}}$ & $2.81^{\text {ns }}$ & 33.18 & 14.44 & $0.08^{\mathrm{ns}}$ & $3.85^{*}$ \\
\hline recuperation behavior & 1.25 & 0.39 & $4.10^{\mathrm{ns}}$ & $6.20^{* *}$ & 5.14 & 2.06 & $0.77^{\mathrm{ss}}$ & $0.04^{\mathrm{ss}}$ \\
\hline mobile behavior & 7.16 & 1.36 & $7.80^{\text {ns }}$ & $1.09^{\text {ns }}$ & 6.57 & 2.28 & $0.08^{\mathrm{ns}}$ & $1.19^{\mathrm{ns}}$ \\
\hline leaving bedroom & 380.99 & 21.67 & $6.63^{\mathrm{ns}}$ & $3.49^{\mathrm{ns}}$ & 271.20 & 89.49 & $2.14^{\mathrm{ns}}$ & $1.19^{\mathrm{ns}}$ \\
\hline
\end{tabular}

\section{Discussion}

Three limitations of the present study are as follows. First, the staff of the organizations plan the daily schedules of the residents, such as fixed times for meals (breakfast, 7:00AM; lunch, 11:00AM; tea time, 15:00PM; supper, 17:00PM), diaper changing, bathing, watching television, visiting the doctor, rehabilitation, etc. Kumsuek et al. (1994) pointed out that since the residents completely submit themselves to the organization's management, the organization plans their day-to-day activities, and the residents live as per the relevant regulations. Since the residents analysed in this study were also subjected to the influences of the organization's schedule, this study opted to analyse their behavior in their bedrooms, where the organization has little influence, in order to obtain results reflecting the actual situation of the residents.

The second limitation was that the organization primarily had six-person rooms, with only a few twobed bedrooms. As per organizational policy, only residents with serious disabilities, or a tendency to disturb other residents, would be moved to twoperson bedrooms, this is in order to avoid infection or interference. Therefore, the sample size of residents without dementia or illnesses was significantly small.

Third, there was a large difference in subjects between two-person bedrooms and six-person bedrooms, meaning the time it took to observe and record the residents' behavior. Thus, only a limited number of residents were selected as subjects of the study, conducted through a non-random sampling pattern, since these factors may influence the results. Thus, the results of this study must be carefully considered as they may reflect the data collection pattern.

Topic suggestions that require further investigation in order to acquire a more holistic view.

\subsection{Significance of ADL to day-to-day behavior}

The results show that ADL does not influence the day-to-day behaviors of residents in either kind of shared bedroom. The results must be analysed with 
care, as ADL is an important indicator to examine the physical functions of the elderly. The assessment results of ADL can be used to distinguish between the degree of different disabilities, serve as reference for ADL training and treatment, assess the quality of care, predict care demands, etc. (Chang et al., 2006). Thus, ADL assessment is an important aspect of future study in this field. Past studies analysing in-room behaviors have also concluded that attention should be given to the ADL of residents, and that future studies should analyse the demand for different kinds of bedroom designs (Tzeng and Wang, 2002).

The International Classification of Functioning, Disability, and Health (ICF), as put forward by the World Health Organization (WHO), mentioned that the ICF has three classifications, namely, body functions and structure, activities, and involvement. Under the framework of the ICF, limitations of body functions depend on assistance from external environments provided to an individual; however, it does not fully assess personal capacity or the state of body and mind. The interpretation of this result, as per the ICF, suggests that the influence of ADL on body functions is an important indicator; however, for residents already living in the organization, apart from body functions, greater significance is attached to their behaviors, and meaningful care should be provided.

\subsection{Social withdrawal behavior}

According to environmental psychology, withdrawal behavior is usually expressed in high density spaces, presented in the form of leaving, avoiding topics of discussion, making negative gestures, changing directions, etc. (Gifford, 2005). Studies point out that the quiet behavior of residents is mainly a bodily function that requires others' care (Kumsuek et al., 1994). Inoue et al. (1997) proposed that shared bedrooms, despite the lack of privacy, increase the quiet behavior of residents. While the present study shows that there is no difference in body functions of daily life behaviors, the occurrence of quiet behavior is consistent with the results of past researches.

According to Keen (1989), three important points of privacy are the senses of sight, sound, and smell. By observing a plane graph, it can be seen that there is no isolation of sight, sound, or smell in two-person and six-person rooms. The most frequently occurring behaviors in two-person and six-person rooms are leaving the bedroom and quiet behavior, that is, social withdrawal behaviors.

Furthermore, apart from the daily schedule of activities, as prescribed by the organization, studies show that when the organization provides diversified public spaces, the ratio of residents' remaining in their bedrooms is lowered (Yi and Taniguchi, 1998; Lawton et al., 1984). Obviously, this aspect requires further study in order to understand the influence of other organizational spaces on the residents' behaviors.

\subsection{Factors to be considered in cases of shared bedrooms}

The time spent on recuperation behaviors is four times greater in six-person rooms. Organizations usually keep residents with serious dementia, or those who tend to disturb others, in two-person rooms in order to avoid disturbing the other residents. This is consistent with the results of a study conducted by Yang (2001). Residents do not like sharing rooms with people who have serious diseases, or those who are on their deathbeds.

Furthermore, there is a difference between the recuperation behaviors of residents with, and without dementia, in six-person rooms, and their social interaction behaviors in two-person rooms. From the perspective of time, time spent on recuperation and social interaction behaviors, by residents with dementia, is less than that of residents without dementia, which shows that residents suffering from dementia have no great requirements in recuperation behaviors, and have difficulty communicating with their roommates. Investigations by past researchers have shown that residents suffering from dementia tend to disturb those without dementia, leading to the suggestion that dementia patients should live in smaller organizations, or should not share a room with other residents (Hsu et al. 2004). Studies also point out that residents living in small organizations tend to maintain their current level, or improve their competence in ADL, leading to decreased problematic behaviors, and increased satisfaction, voluntary activities, etc. (Hisano and Shimizu, 2003). This study supports the results of past studies.

There is a difference between caring for residents suffering from dementia and those with serious injuries. Thus, physical condition and recognition of residents are factors to consider when an organization plans roommates.

\subsection{Study on privacy, from the perspective of basic behavior and social interaction behavior}

There are statistical differences between the basic behaviors of residents sharing six-person rooms and those sharing two-person rooms. The time spent on basic behaviors by residents sharing two-person rooms is more than 1.6 times that of residents sharing sixperson rooms. On the other hand, time spent on the basic behaviors of cleaning is nine times greater in two-person rooms than in six-person rooms. This may be a result of organizations moving residents with serious dementia to two-person bedrooms. In addition, time spent on basic behaviors, such as dietary intake, excretion, sorting personal items, etc. in two-person rooms is more than 1 time that of six-person rooms; while dressing takes up more than twice the amount of time in six-person rooms. Studies on privacy and space show that when residents have privacy in their own rooms, they feel they can freely express themselves and 
their personality in their room. From the perspective of time, residents in two-person rooms tend to have a more behaviors, through which they express their personality in their room.

With regard to social interaction behaviors, Bitzan (1998) mentioned that residents could provide emotional support to their roommates. Though a social interaction behavior of two-person rooms was greater than in the six-person rooms, there was a high standard deviation. While there was emotional support in the two-person rooms, there may be differences in time spent on social interactions with roommates. However, time spent on social interaction behaviors is inconsistent with the results of past studies, and this study found that a higher number of roommates tend to decrease social interaction behaviors.

This result shows that in spaces without screening to provide some degree of privacy, both two-person rooms and six-person rooms will increase the residents' quiet and leaving the bedroom behaviors (social withdrawal behavior), but will decrease their basic and social interaction behaviors. In rooms without screening, if the number of roommates is small, residents may express their personality.

\section{Acknowledgments}

Part of this research was supported by the National Science Council, Taiwan, R.O.C., under contract no. NSC 95-2314-B-468-001-.

\section{References}

1) Bitzan, J. (1998) Emotional bondedness and subjective well-being between nursing home roommates. Journal of Gerontological Nursing, 24(9), pp.8-15.

2) Bowie, P., Mountain, G., Clayden, D. (1992) Assessing the environmental quality of longstay wards for the confused elderly. International Journal of Geriatric Psychiatry, 7(2), pp.95-104.

3) Chang, H.Y., Hsieh, Y.W., Huseh, I.P., Hsieh, C.L., (2006) A forty-year retrospective of assessment of activities of daily living. Taiwan Journal of Physical Medicine and Rehabilitation, 34(2), pp.63-71.

4) Chang, Y.H., Wu, C.M. (2003) Nursing Experience with a Hopelessness Case in a Nursing Home. The Journal of Nursing, 50(3), pp.99-104.

5) Chaudhury, H., Mahmood, A. and Valente, M. (2005) Advantages and disadvantages of single versus multiple-occupancy rooms in acute care environments. Environment and Behavior, 37(6), pp.760-786.

6) Chuang, H.M. (2008) Discussion on the environmental construction and practical ideas of "unit care" service model. NTU Social Work Review, 16, pp.87-128.

7) Duffy, M., Bailey, S., Beck, B. and Barker, D.G. (1986) Preferences in nursing home design: A comparison of residents, administrators, and designers. Environment and Behavior, 18(2), pp.246-257.

8) Foltz-Gray, D. (1995) Intimate strangers. When roommates clash, caregivers can ease the tension--or make it worse. Contemporary Long Term Care, 18(6), pp.34-37.

9) Gifford, R. (2005) Chapter 7: Crowding, Japanese translation of Environmental Psychology: Principles and Practice. Tokyo, Kitaohji Shobo, pp.260-307.
10) Harris, P.B., McBride, G., Ross, C. and Curtis, L. (2002) A place to Heal: Environmental sources of satisfaction among hospital patients. Journal of Applied Social Psychology, 32(6), pp.1276-1299.

11) Hisano, S., Shimizu, H. (2003) Finding a physical environment desirable for elderly residential facilities: A survey of the literature. Journal of health sciences, Hiroshima University. 3(1), pp.21-36.

12) Hsu, P.J., Hwang, Y.R., Len, G.C., Chen, Y.H., Loh, C.H., Lee, S.D. (2004) The possible impact of living status on problem behaviors of demented patients in care units. Taiwan Journal of Family Medicine, 14(1), pp.13-24.

13) Huang, S.L., Hui-Yin Liu, H.Y., Hsu, H.Y. (2008) Research of Unit Care in the Medicare Institution: A Case Study in Pingtung. NTU Social Work Review, 16, pp.129-166.

14) Inoue, Y., Toyama, T., Otaki, K. and Ohar, K. (1997) A study on the difference of personalization between single bed room and plural beds room: A study on nursing home with single bed rooms (part 3). Summaries of technical papers of Annual Meeting Architectural Institute of Japan. E-1, pp.123-124.

15) Inoue, Y., Toyama, T., Otaki, K. and Ohara, K. (1997) A study on the personalization of residents in nursing home: Studies on social welfare institution for the elderly from the aspect of dwelling. Journal of architecture, planning and environmental engineering, Transactions of AIJ, 501, pp.109-115.

16) Kahana, E. (1982). A congruence model of person-environment interaction. In M. P. Lawton, P. G.Windley, \& T. O. Byerts (Eds.), Aging and the environment (pp. 97-121). New York: Springer.

17) Kaldenburg, D.O. (1999). The influence of having a roommate on patient satisfaction. Press Ganey Satisfaction Monitor.

18) Kane, R.A., Baker, M.O., Salmon, J., Veazie, W. (1998) Consumer perspectives on private versus shared accommodations in assisted living settings. Washington, DC: American Association of Retired Persons, Public Policy Institute.

19) Keen, J. (1989) Interiors: Architecture in the lives of people with dementia. International Journal of Geriatric Psychiatry, 4(5), pp.255-272.

20) Koga, T., Takahashi, T., Toyama, T., Tachibana, H. (2002) A Study On The Meaning Of Possessions For Environmental Transition: The actual conditions and meaning of possessions belonging to elderly persons who live in nursing homes. Journal of architecture, planning and environmental engineering, 551, pp.123-127.

21) Kumsuek, Y., Koji, S. and Jun, U. (1994) The daily living activities of the aged in recuperation facilities - A study on the rationalization of recuperation environment for the aged. Architectural Institute of Japan, 466, pp.37-46.

22) Lawton, M.P. (2001) The physical environment of the person with Alzheimer's disease. Aging and Mental Health, 5(2), pp.56-64.

23) Lawton, M.P., Eisdorfer, L. (1973). The psychology of adult development and aging. Washington, DC, US: American Psychological Association. pp.619-674.

24) Lawton, M.P., Fulcomer, M. and Kleban, M.H. (1984) Architecture for the mentally impaired elderly. Environment and Behavior, 16(6), pp.730-757.

25) Lewin, K. (1951) Field theory in social science. New York: Harper \& Row.

26) Moos, R.H. and Lemke, S. (1996) Evaluating Residential Facilities: The Multiphasic Environmental Assessment Procedure. Sage, London.

27) Morgan, D.G., Stewart, N.J. (1999) The physical environment of special care units: Needs of residents with dementia from the perspective of staff and family caregivers. Qualitative Health Research, 9(1), pp.105-118.

28) Mosher-Ashley, P. and Lemay, E. (2001) Improving residents' life satisfaction. Nursing Homes and Long-Term Care Management Magazine, 50, pp.50-54

29) Nakanishi, J. (2004) Concept analysis of "daily life behavior". Bulletin of Ehime College of Health Science, 1(1), pp.49-56. 
30) Sloane, P.D., Mitchell, C.M., Weisman, G., Zimmerman, S., Long Foley, K.M., Lynn, M., Calkins, M., Lawton, M.P., Teresi, J., Grant, L., Lindeman, D. and Montgomery, R. (2002) The therapeutic environment screening survey for nursing homes (TESS-NH): An observational instrument for assessing the physical environment of institutional settings for persons with dementia. Journal of Gerontology: Social Sciences, 57(2), pp.69-78.

31) Sumeragi, T., Koga, T., Kojima, T., Munakata, J. and Hirate, K. (2002) A study of the viewpoint of the residents of welfare facility for the aged: User's evaluation of welfare facility for the aged (Part 4). Summaries of technical papers of Annual Meeting Architectural Institute of Japan, E-1, pp.929-930.

32) Tachibana, H., Toyam, T., Takahashi, T. and Koga, T. (1997) A study on personalization in private room of nursing home for the elderly. Journal of Architecture, Planning and Environmental Engineering. 500, pp.133-138.

33) Terakawa, Y. (2004) The relationship between environment and behavior at the institutional setting for the elderly. Paper presented at the Environmental Design Research Association 35th Annual Conference, Albuquerque, NM.

34) Tzeng, S.Y., Wang, L.F. (2002) An investigation on the using behavior of bedroom in long term care facility for the elderly by the case of thirteen nursing homes in Kaoshiung area. Journal of Architecture, 39, pp.1-21.

35) Ulrich, R. and Zimring, C. (2004) The Role of the Physical Environment in the Hospital of the 21st Century: A Once-in-aLifetime Opportunity, CA: Center for Health Design.

36) Wang, C.H., and Kou, N.W. (2005) Architectural evolution of long-term care facilities. Taipei City Medical Journal, 2(4), pp.311-319.

37) Westin, A.F. (1967). Privacy and Freedom. New York: Atheneum

38) Willcocks, D., Peace, S. and Kellaher, L. (1987) Private Lives in Public Places: A Research based Critique of Residential Life In Local Authority Old People's Homes. London, Tavistock.

39) Yang, C.L. (2001) Indicators of quality of care for nursing homes: from the perspectives of residents, family, and nurses. Taiwan Journal of Public Health, 20(3), pp.239-247.

40) Yi, H., Taniguchi, G. (1998) A study on the elderly behavior in public spaces of elderly facilities. Summaries of technical papers of Annual Meeting Architectural Institute of Japan, E-1, pp.503-504 